\title{
Association between Cardiac Remodeling and Metabolic Alteration in an Experimental Model of Obesity Induced by Western Diet
}

\author{
Artur Junio Togneri Ferron ${ }^{1, * \mathbb{C}}$, Fabiane Valentini Francisqueti ${ }^{1}{ }^{(\mathbb{C}}$, Igor Otávio Minatel ${ }^{2} \mathbb{(}$, \\ Carol Cristina Vágula de Almeida Silva ${ }^{1}$, Silméia Garcia Zanati Bazan ${ }^{1}$ (D), \\ Koody André Hassemi Kitawara ${ }^{1}$, Jéssica Leite Garcia ${ }^{1} \mathbb{D}$, Camila Renata Corrêa ${ }^{1} \mathbb{D}$, \\ Fernando Moreto $^{1}$ (D) and Ana Lucia A. Ferreira ${ }^{1}$ \\ 1 São Paulo State University (Unesp), Medical School, Botucatu 18618-687, Brazil; \\ fabianevf@gmail.com (F.V.F.); carolvagula@gmail.com (C.C.V.d.A.S.); sgzanati@fmb.unesp.br (S.G.Z.B.); \\ kodiro@gmail.com (K.A.H.K.); jessleitegarcia@gmail.com (J.L.G.); correa.camila9@gmail.com (C.R.C.); \\ fer_moreto@yahoo.com.br (F.M.); ferreira@fmb.unesp.br (A.L.A.F.) \\ 2 São Paulo State University (Unesp), Institute of Biosciences, Botucatu 18618-689, Brazil; \\ igorminatel@hotmail.com \\ * Correspondence: artur.ferron@gmail.com; Tel.: +55-14-3880-1171; Fax: +55-14-3882-2238
}

Received: 4 September 2018; Accepted: 25 October 2018; Published: 5 November 2018

\begin{abstract}
The high consumption of fat and sugar contributes to the development of obesity and co-morbidities, such as dyslipidemia, hypertension, and cardiovascular disease. The aim of this study was to evaluate the association between dyslipidemia and cardiac dysfunction induced by western diet consumption. Wistar rats were randomly divided into two experimental groups and fed ad libitum for 20 weeks with a control diet (Control, $n=12$ ) or a high-sugar and high-fat diet (HSF, $n=12)$. The HSF group also received water + sucrose $(25 \%)$. Evaluations included feed and caloric intake; body weight; plasma glucose; insulin; uric acid; HOMA-IR; lipid profile: [total cholesterol (T-chol), high-density lipoprotein (HDL), non-HDL Chol, triglycerides (TG)]; systolic blood pressure, and Doppler echocardiographic. Compared to the control group, animals that consumed the HSF diet presented higher weight gain, caloric intake, feed efficiency, insulin, HOMA-IR, and glucose levels, and lipid profile impairment (higher TG, T-chol, non-HDL chol and lower HDL). HSF diet was also associated with atrial-ventricular structural impairment and systolic-diastolic dysfunction. Positive correlation was also found among the following parameters: insulin versus estimated LV mass $(r=0.90, p=0.001)$; non-HDL versus deceleration time $(r=0.46, p=0.02)$; TG versus deceleration time $(r=0.50, p=0.01)$. In summary, our results suggest cardiac remodeling lead by western diet is associated with metabolic parameters.
\end{abstract}

Keywords: dyslipidemia; obesity; cardiac remodeling

\section{Introduction}

Obese individuals are typically predisposed to an increased heart rate and stroke volume, which may lead to ischemic cardiomyopathy, compensatory left ventricular remodeling, non-ischemic dilated cardiomyopathy, cardiac fibrosis, and apoptosis [1]. Furthermore, obesity is associated with metabolic syndrome (MS), a clustering of risk factors that includes visceral obesity, dyslipidemia, hyperglycemia, and hypertension. Among these factors, dyslipidemia is the major risk factor for cardiovascular disease (CVD). Although obesity influences blood lipid and lipoprotein levels, dietary factors are also able to influence these parameters [2]. 
Western diets (WD), which are rich in fat and carbohydrates may be responsible for the obesity epidemic, especially in industrialized countries [1]. WD are characterized by the consumption of high caloric-dense foods, and unbalanced proportions of fat (saturated vs unsaturated) and carbohydrates (high glycemic vs low glycemic), eating habits associated with an increased CVD risk [3]. Sonestedt et al. observed that individuals with low sucrose intake had lower triglycerides and higher HDL concentrations compared to those with high sucrose consumption [2]. Moreover, it has been already confirmed that the consumption of high carbohydrate foods and beverages increases the risk of MS [4].

There are several spontaneous (genetic) rodent models for MS that present cardiovascular disorders, including Zucker diabetic fatty rats [5,6], Goto-Kakizaki rats [7], and spontaneously hypertensive rats [8]. Although these models provide important information regarding the pathogenesis and the treatment of some aspects of MS, they do not reflect the diet-induced human metabolic syndrome [9]. Therefore, appropriate animal models mimicking human metabolic syndrome and related CVD are necessary to investigate the causes and progression of this disease and potential pharmacological interventions [10,11].

Experimental studies regarding cardiac function and diet-induced obesity present divergent results. Rats fed hypercaloric diets for 8 to 14 weeks developed obesity [12-14], but not cardiac disfunction, as assessed by echocardiogram [13,14]. However, Panchal et al. [15] showed ventricular dilation, increased systolic volume and increased estimated left ventricular mass in rats fed with high-carbohydrate and high-fat diet for both 8 and 16 weeks. Moreover, other researchers found diastolic dysfunction in isolated heart and papillary muscles [16], reduction in diastolic compliance [17] and impaired mechanical function of ventricular myocytes [18] from Ob rabbits [12,18] and rats [19] fed high-fat diets for 12 weeks. In this way, this study was designed to verify the hypothesis that our proposed diet model is able to induce cardiac remodeling. So, the aim of this study was to evaluate the effect of a Western diet on cardiac remodeling and its association with metabolic parameters.

\section{Materials and Methods}

\subsection{Animals and Experimental Protocol}

All the experimental protocol was approved by the Ethics Committee on the Use of Animals (CEUA) from Botucatu Medical School, São Paulo State University (UNESP), under number 1196/2016. Male Wistar rats (5-6 weeks old, weighing $209 \pm 18 \mathrm{~g}, n=24)$ were obtained from the Animal Center of Botucatu Medical School, São Paulo State University, UNESP (Botucatu, SP, Brazil) and randomly divided into 2 experimental groups to receive chow diet (control group, $n=12$ ) or high-sugar high-fat diet (HSF, $n=12$ ) for 20 weeks. Animals were individually housed in temperature-controlled and 12-hour light-dark conditions. Diets were designed in our laboratory and previously published by our research group [20]. The control diet contained soybean meal, sorghum, soybean hulls, dextrin, soy oil, vitamins and minerals. The HSF diet was composed of soybean meal, sorghum, soybean hulls, dextrin, sucrose, fructose, lard, vitamins and minerals plus $25 \%$ sucrose in drinking water. Nutritional composition of both diets is presented in Table 1, without considering drinking water.

Table 1. Nutritional composition of the diets.

\begin{tabular}{ccc}
\hline & \multicolumn{2}{c}{ Diet } \\
\hline Ingredients & Control & HSF \\
\hline Soybean meal $(\mathrm{g} / \mathrm{kg})$ & 335 & 340 \\
Sorghum $(\mathrm{g} / \mathrm{kg})$ & 278 & 80 \\
Soy hulls $(\mathrm{g} / \mathrm{kg})$ & 188.5 & 116.7 \\
Dextrin $(\mathrm{g} / \mathrm{kg})$ & 146.5 & 20 \\
Sucrose $(\mathrm{g} / \mathrm{kg})$ & - & 80 \\
Fructose $(\mathrm{g} / \mathrm{kg})$ & - & 180 \\
\hline
\end{tabular}


Table 1. Cont.

\begin{tabular}{ccc}
\hline & \multicolumn{2}{c}{ Diet } \\
\hline Ingredients & Control & HSF \\
\hline Soy oil $(\mathrm{g} / \mathrm{kg})$ & 14 & - \\
Lard $(\mathrm{g} / \mathrm{kg})$ & - & 154.3 \\
Minerals $(\mathrm{g} / \mathrm{kg})$ & 25 & 25 \\
Salt $(\mathrm{g} / \mathrm{kg})$ & 4 & 8 \\
\hline Components & & \\
Protein $(\%)$ & 20 & 16 \\
Carbohydrate $(\%)$ & 60 & 70 \\
Fat $(\%)$ & 4 & 14.6 \\
$\%$ Energy from protein & 22.85 & 13.45 \\
$\%$ Energy from carbohydrate & 66.78 & 58.69 \\
\% Energy from fat & 10.37 & 27.8 \\
Energy (kcal/g) & 3.59 & 4.35 \\
\hline
\end{tabular}

HSF diet had $25 \%$ of sucrose in drinking water.

\subsection{Nutricional Profile}

Feed consumption (FC) was measured daily and body weight (BW) was assessed weekly. Caloric intake (CI) for the control group was calculated according to the following formula: caloric intake $(\mathrm{kcal} /$ day $)=$ feed consumption $(\mathrm{g}) \times$ dietary energy $(3.59 \mathrm{kcal} / \mathrm{g})$. For the animals that received the HFS diet, the energy intake was calculated according to the formula: volume consumed $(\mathrm{mL}) \times 0.25$ (equivalent to $25 \%$ fructose) $\times 4$ (calories per gram of carbohydrate) + caloric values offered by feeding (feed consumption $(\mathrm{g}) \times$ dietary energy $(4.35 \mathrm{kcal} / \mathrm{g})$. Feed efficiency $(\mathrm{FE})$ is the ability to convert caloric intake to $\mathrm{BW}$ and it was determined as follows: $\mathrm{FE}(\%)=\mathrm{BW}$ gain $(\mathrm{g}) /$ total caloric intake $(\mathrm{kcal})$ $\times 100[16]$.

\subsection{Plasma Measurements}

After 12-h fasting, blood was collected from the tail and the plasma was used for biochemical analysis. Plasma glucose was determined by using a glucometer (Accu-Chek Performa; Roche Diagnostics, Indianapolis, IN, USA). Insulin level was measured by enzyme-linked immunosorbent assay (ELISA) method using commercial kits (Millipore). Triglycerides, total cholesterol, high-density lipoprotein (HDL), urea, and creatinine were measured by an automatic enzymatic analyzer system (Biochemical analyzer BS-200, Mindray, China). Non-HDL cholesterol fraction (VLDL + IDL + LDL) which is considered an estimation of the total atherogenic particles in plasma, was calculated by the formula: (non-HDL Chol = total Cholesterol-HDL) [21].

\subsection{Homeostatic Model Assessment Index (HOMA-IR)}

The homeostatic model of insulin resistance (HOMA-IR) was used as an insulin resistance index, and it was calculated using the following formula: HOMA-IR $=[$ fasting glucose $(\mathrm{mmol} / \mathrm{L}) \times$ fasting insulin $(\mu \mathrm{U} / \mathrm{mL})] / 22.5[16]$.

\subsection{Systolic Blood Pressure (SBP)}

SBP evaluation was assessed in conscious rats by the non-invasive tail-cuff method with a NarcoBioSystems ${ }^{\circledR}$ Electro-Sphygmomanometer (International Biomedical, Austin, TX, USA). The animals were warmed in a wooden box $(50 \times 40 \mathrm{~cm})$ between $38-40{ }^{\circ} \mathrm{C}$ with heat generated by two incandescent lamps for 4-5 min to cause arterial vasodilation in the tail and were then transferred to an iron cylindrical support that was specially designed to allow total exposure of the animal's tail [22]. After this procedure, a cuff with a pneumatic pulse sensor was attached to the tail of each animal. The cuff was inflated to $200 \mathrm{mmHg}$ pressure and subsequently deflated. The blood pressure 
values were recorded on a Gould RS 3200 polygraph (Gould Instrumental Valley View, OH, USA). The average of two pressure readings was recorded for each animal.

\subsection{Echocardiographic Analysis}

At 20th week, all the animals were evaluated in vivo by transthoracic echocardiography, using a Vivid S6 system equipped with multifrequency ultrasonic transducer 5.0 to $11.5 \mathrm{MHz}$ (General Electric Medical Systems, Tirat Carmel, Israel). All exams were performed by the same examiner and obtained according to the leading-edge method recommended by the American Society of Echocardiography. Rats were lightly anesthetized by intramuscular injection with a mixture of ketamine $(50 \mathrm{mg} / \mathrm{kg})$ and xylazine $(1 \mathrm{mg} / \mathrm{kg})$. After shaving their chest, the animals were placed in left decubitus position. To implement structural measures of the heart, the images were obtained in one-dimensional mode (M-mode) guided by the images in two-dimensional mode with the transducer in the parasternal position, minor axis. Left ventricular (LV) evaluation was performed by positioning the cursor M-mode just below the mitral valve plane at the level of the papillary muscles. The images of the aorta and left atrium were obtained by positioning the M-mode course to plan the level of the aortic valve. The following cardiac structures were measured: diastolic diameter (LVDD) and systolic (LVSD) LV; diastolic thickness posterior wall of the left ventricle (LVPWD); diameter of the aorta (DA) and left atrium (LA). The relative thickness of the LV (ERVE) was calculated by dividing LVPWD multiplied by two by LVDD. Left ventricular mass (LVM) was calculated using the formula [(LVDD +LVPWD IVSDT) $3-($ LVDD) 3] $\times 1.04$ where 1.04 is the specific density of the myocardium. MVE index (LVMI) was calculated by normalizing to body weight Estimated LV mass. The LV systolic function was assessed by the following parameters: percentage of endocardial shortening ( $\triangle \%$ endo) [(LVDD - LVSD)/LVDD] $\times 100$; midwall fractional shortening ( $\% \Delta$ meso) $\{$ (LVDD $+1 / 2+1 / 2$ LVPWD IVSDT) $-($ LVSD $+1 / 2+$ $1 / 2$ IVSST LVPWS)]/(LVDD + 1/2 + 1/2 LVPWD IVSDT) $\} \times 100$; shortening velocity rear wall (LVPW), which is the maximum tangent of the stroke movement of the rear wall. The LV diastolic function was evaluated by the following indices: peak velocity of early diastolic filling (E wave); peak velocity of late diastolic filling (A wave); ratio between the $\mathrm{E}$ and $\mathrm{A}$ waves (E/A); deceleration time of $\mathrm{E}$ wave (DTE); isovolumetric relaxation time in absolute values (IRT) and normalized for heart rate (TRIVn = IRT/R-R0,5). The joint assessment of diastolic and systolic LV function was performed by myocardial performance index also known as Tei index (sum of isovolumetric contraction and IRT time, divided by the left ventricular ejection time). The study was supplemented by evaluation by tissue Doppler systolic displacement $\left(\mathrm{S}^{\prime}\right)$, early diastolic $\left(\mathrm{E}^{\prime}\right)$, and late $\left(\mathrm{A}^{\prime}\right)$ of the mitral annulus (arithmetic average travel speeds of lateral and septal walls), and the ratio by the waves $E$ and $E^{\prime}\left(E / E^{\prime}\right)[23,24]$.

\subsection{Statistical Analysis}

Data are presented as mean \pm standard deviation (SD) or median (interquartile range). Differences between the groups were determined by using Students-t test for independent samples. Pearson correlation was used for analytical statistic for association between cardiac parameters and metabolic variables. All statistical analyses were performed using SigmaStat for Windows (Version 3.5). $p$ value $<0.05$ was considered as statistically significant.

\subsection{Results}

After 20 weeks of treatment simulating a western diet, the HSF group showed higher weight gain than the control group. Even with a lower feed consumption, the HSF group showed higher caloric intake that resulted in higher feed efficiency (Figure 1).

In addition, the western diet induced changes in glucose metabolism homeostasis, characterized by higher glucose, insulin and HOMA-IR compared to the control group (Table 1).

The western diet was also associated with systolic and diastolic cardiac dysfunction, and remodeling at 20th week (Table 2), and changes in plasma lipid profile-higher TG, TC, non-HDL, and lower HDL (Figure 2). 
Table 2. Effect of high-sugar and high-fat (HSF) diet on plasma metabolic parameters.

\begin{tabular}{ccc}
\hline & \multicolumn{2}{c}{ Groups } \\
\hline Variables & Control $(n=12)$ & HSF $(n=12)$ \\
Glucose $(\mathrm{mg} / \mathrm{dL})$ & $83.4 \pm 6.3$ & $97.9 \pm 8.5^{*}$ \\
Insulin $(\mathrm{mg} / \mathrm{dL})$ & $2.5 \pm 1.2$ & $5.2 \pm 1.3^{*}$ \\
HOMA-IR & $21.3 \pm 9.6$ & $50.7 \pm 11.2 *$ \\
\hline
\end{tabular}

Data presented as means \pm SD. Control and high-sugar high-fat (HSF) groups; $n$ : animals numbers; HOMA-IR: homeostatic model assessment index; ${ }^{*} p<0.05$ versus $C$; Student's $t$-test for independent samples.
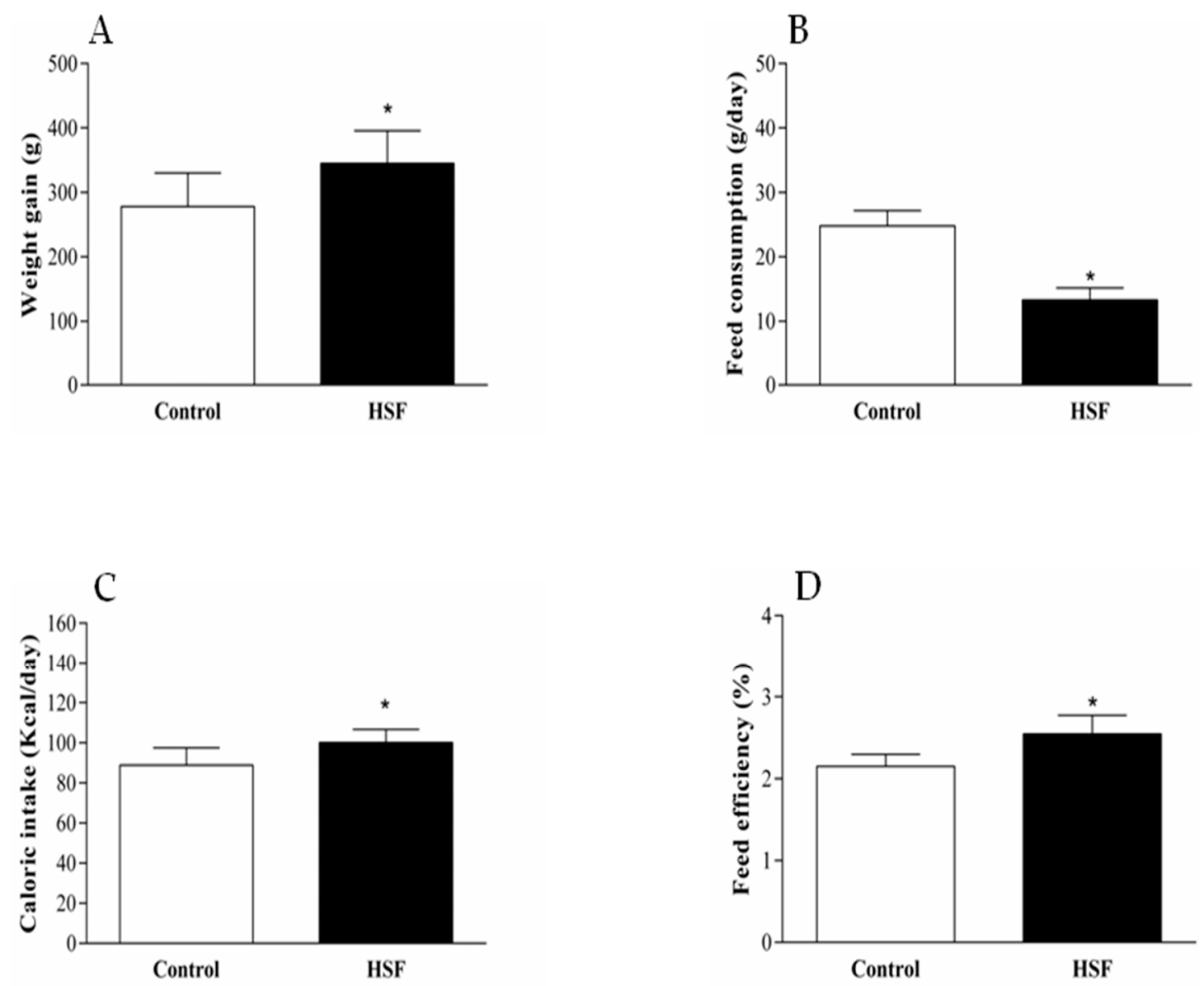

Figure 1. Nutritional profile of the groups. (A) weight gain (g); (B) feed consumption (g/day); (C) caloric intake(kcal/day); (D) feed efficiency (\%). HSF-high-sugar high-fat group. * indicates $p<0.05$.

The cardiac variables and systolic blood pressure are presented in Table 3. The diet promoted an increase in systolic blood pressure, cardiac remodeling, and deterioration of cardiac function, visualized by echocardiogram analysis.

Table 3. Effect of HSF diet on hemodynamic and cardiac remodeling.

\begin{tabular}{ccc}
\hline \multirow{2}{*}{ Variables } & \multicolumn{2}{c}{ Groups } \\
\cline { 2 - 3 } & Control $(\boldsymbol{n}=\mathbf{1 2})$ & HSF $(\boldsymbol{n}=\mathbf{1 2})$ \\
\hline LVDD, mm & $7.50 \pm 0.40$ & $6.53 \pm 0.49^{*}$ \\
LVSD, mm & $2.68 \pm 0.34$ & $3.31 \pm 0.44^{*}$ \\
LVPWD, mm & $1.54 \pm 0.11$ & $1.97 \pm 0.11^{*}$ \\
Aorta diameter, mm & $3.79 \pm 0.24$ & $4.01 \pm 0.19^{*}$ \\
Left Atrium & $4.73 \pm 0.20$ & $6.17 \pm 0.41^{*}$ \\
\hline
\end{tabular}


Table 3. Cont.

\begin{tabular}{ccc}
\hline \multirow{2}{*}{ Variables } & \multicolumn{2}{c}{ Groups } \\
\cline { 2 - 3 } & Control $(\boldsymbol{n = 1 2})$ & HSF $(\boldsymbol{n = 1 2})$ \\
\hline Estimated LV mass, g & $1.56 \pm 0.32$ & $2.03 \pm 0.23 *$ \\
Relative wall thickness & $0.45 \pm 0.03$ & $0.58 \pm 0.06$ * \\
Systolic volume, mL & $23.5 \pm 2.8$ & $26.6 \pm 5.8$ \\
Shortening $\Delta \%$ endo & $58.2 \pm 3.3$ & $52.5 \pm 55.3 *$ \\
Shortening $\Delta \%$ meso & $25.6 \pm 2.1$ & $25.3 \pm 2.7$ \\
Ejection fraction, \% & $0.92 \pm 0.01$ & $0.89 \pm 0.03 *$ \\
Deceleration time, MS & $44.1 \pm 7.8$ & $53.4 \pm 9.4^{*}$ \\
Ew, m/s & $78.9 \pm 8.4$ & $77.9 \pm 6.6$ \\
Aw, m/s & $48.7 \pm 11.6$ & $45.9 \pm 14.1$ \\
E/A, m/s & $1.67 \pm 0.27$ & $1.85 \pm 0.64$ \\
IRT & $22.9 \pm 3.1$ & $28.1 \pm 4.8^{*}$ \\
Systolic blood pressure, mmHg & $126 \pm 5$ & $136 \pm 5 *$ \\
\hline
\end{tabular}

Data presented as means \pm SD. Control and high-sugar high-fat (HSF) groups; $n$ : animals numbers; LV:Left ventricular; LVDD:Left ventricular diastolic diameter; LVSD:Left ventricular systolic diameter; LVPWD:diastolic posterior wall thickness; Aw: A-wave mitral inflow velocity; Ew: E-wave mitral inflow deceleration time; IRT: Isovolumetric relaxion time; * $p<0.05$ versus Control; Student's $t$-test for independent samples.

A

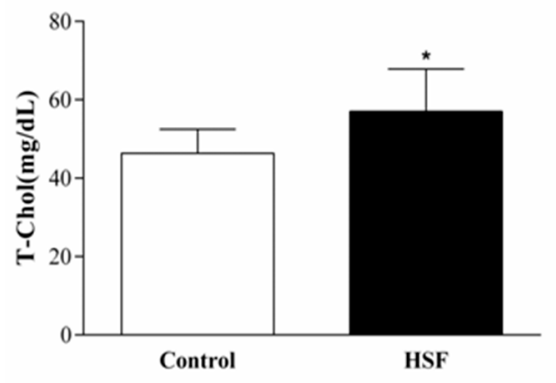

C

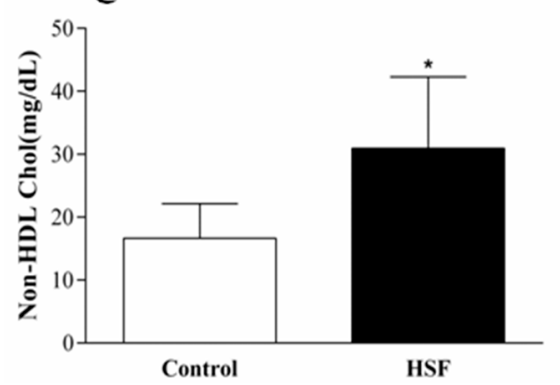

B

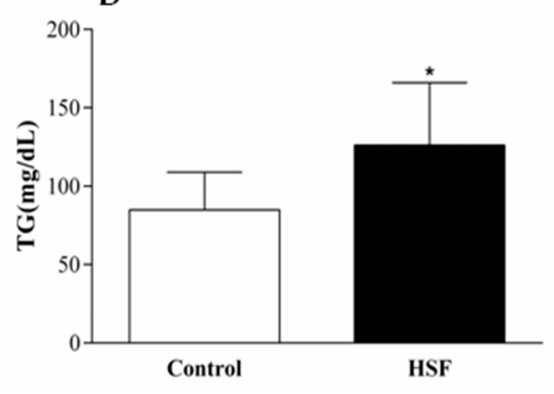

$\mathrm{D}$

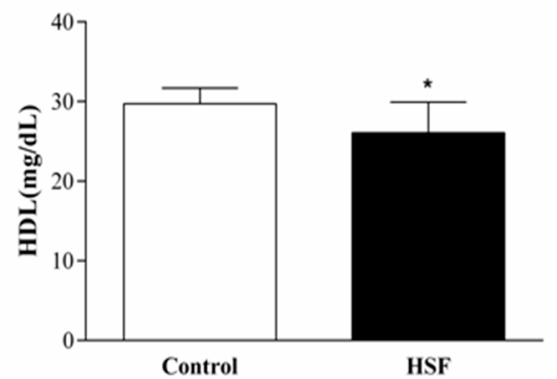

Figure 2. Effect of HSF diet on lipid profile. (A) T-Chol: Total Cholesterol (mg/dL); (B) TG: Triglycerides (mg/dL); (C) Non-HDL Chol:(mg/dL); (D) HDL: High-density lipoprotein (mg/dL). Control group; HSF-high-sugar high-fat group. ${ }^{*}$ indicates $p<0.05$.

Moreover, these cardiac changes were related to the altered lipid profile (Figure 3). Ejection fraction was inversely correlated with non-HDL cholesterol $(r=0.35 ; p=0.09)$ and directly correlated with HDL cholesterol $(r=0.39, p=0.06)$, although marginally significant. Positive correlation was also found among the following parameters: insulin vs. estimated LV mass $(r=0.90, p=0.001)$; non-HDL cholesterol vs. deceleration time $(r=0.46, p=0.02)$; TG vs. deceleration time $(r=0.50, p=0.01)$. 


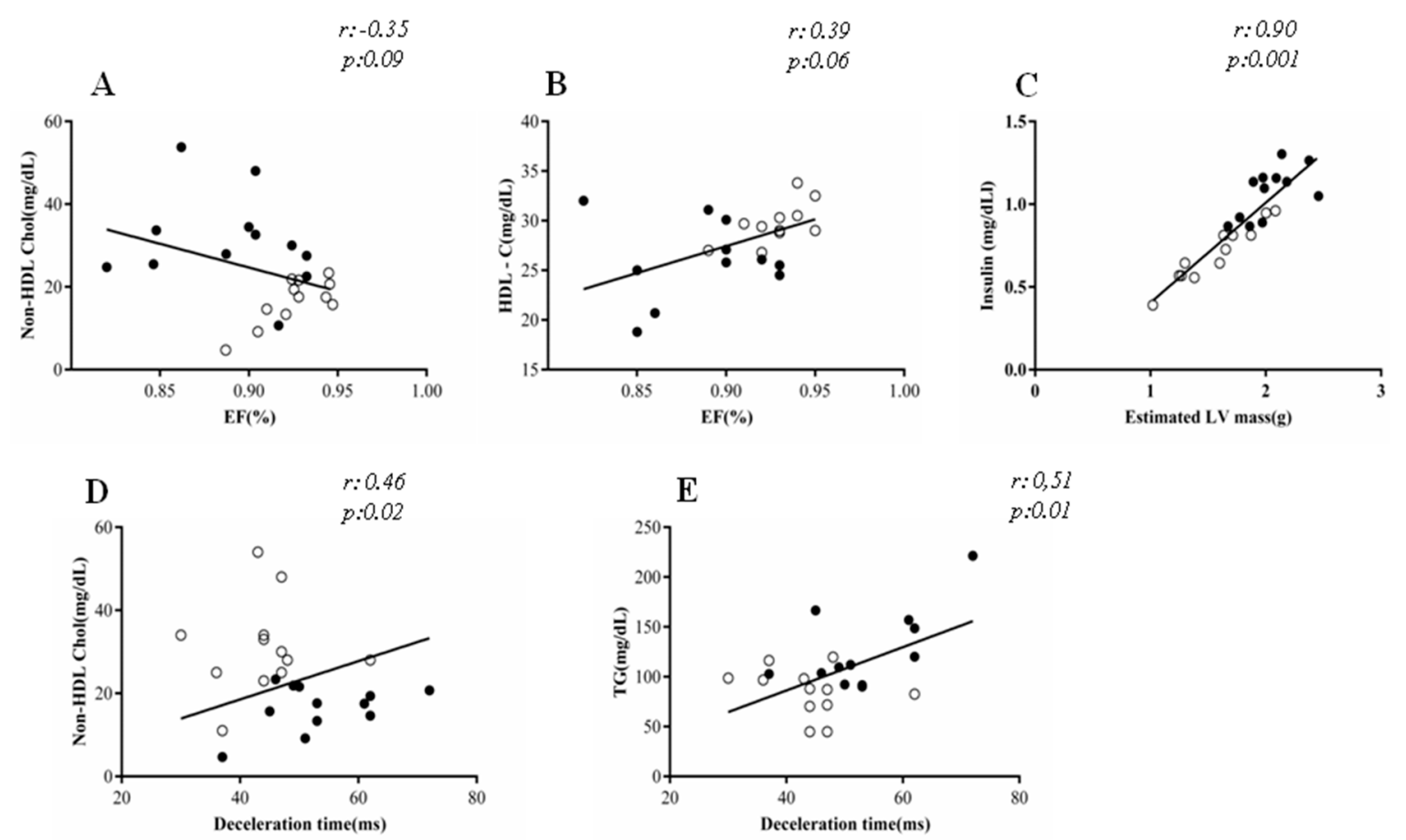

Figure 3. Correlation between echocardiographic and biochemical parameters. EF: Ejection Fraction; (A) Non-HDL Chol:(mg/dL)/EF; (B) TG: HDL: High-density lipoprotein(mg/dL)/EF; (C) Insulin:(mg/dL)/estimated LV mass; (D) Non-HDL Chol:(mg/dL)/Decelaration time and (E) Triglycerides (mg/dL)/Decelaration time. Control group $(\bigcirc)$, HSF group $(\bullet)$; Pearson regression was used to examine the associations between variables.

\section{Discussion}

There is a lack of studies in the literature regarding cardiac function injuries and remodeling in obesity/MS models induced by western diets. The present study showed that the western diet model used was able to induce obesity, MS, and cardiac dysfunction and remodeling in the HSF group, even with a lower feed intake than that observed in control group. Since western diet combines high levels of fat and sugar, resulting in tasty but caloric food, the results can be explained by the better feed efficiency in the HSF group. This diet is the closest equivalent to the human ultra-processed food diet (western diet), and provided the animals with varied nutrients, high energy, and palatability, thereby mirroring the key obesogenic features of the human diet [25].

The development of obesity, characterized in this study by the significant difference in body weight, has occurred in the sixth week of experimental treatment and remained for more 14 weeks, with the HSF group presenting higher values compared to the control group. This result shows that the western diet used was efficient to promote obesity in the experimental period of 20 weeks. According to the literature, western diet/ hypercaloric diets are associated with higher body weight in rodents $[12,18,26,27]$. Besides, the HSF animals in this study also presented many disorders similar to human obesity-related comorbidities, such as hypertension, dyslipidemia hypertriglyceridemia, glucose intolerance, insulin resistance, and hyperinsulinemia. Diets with high sugar and fat are extensively used to induce obesity and MS [28-30], hyperinsulinaemia, hyperglycemia and hepatic steatosis [15], dyslipidemia [31], and elevated blood pressure [32-36].

The cardiac morphological analysis in the current study revealed that the western diet leaded to hypertrophy, as characterized by increased left atrium, aorta diameter, left ventricular diastolic and systolic diameter, estimated mass of left ventricle and relative wall thickness. Moreover, it was also observed cardiac dysfunction, with decreased ejection fraction, shortening $\Delta \%$ endo, and increased deceleration time. All these results show the robustness of the diet to induced cardiac disorders, since most of the experimental studies relating cardiac function and diet- induced obesity present 
divergent results. Some studies using echocardiogram analyses did not find cardiac dysfunction in the obesity model [12,13], whereas, other authors only demonstrated mild changes $[15,37,38]$.

It is known that overweight and obesity can directly and indirectly modulate the heart, either by promoting an increased hemodynamic overload and neurohumoral activation, or by the secretion of proinflammatory adipokines [15,22,39-42]. This initial process of cardiac remodeling may be considered as the first step in the sequence of adaptive responses from heart to the stress leaded by a large number of physiological and pathological conditions, as changes in the volume and pressure loads and/or metabolic changes [43-45]. Rider et al. proposed that cardiac remodeling is an adaptive characteristic of obesity [46]. Thus, obesity-induced changes in cardiac structure may be elicited directly by obesity-induced increases in cardiac loading conditions (preload and afterload) or indirectly by obesity-induced cardiometabolic abnormalities such as dyslipidaemia and insulin resistance/diabetes $[47,48]$. The literature reports that the insulin resistance induced by obesity with associated hyperinsulinemia could promote cardiac remodeling via the growth-promoting properties of insulin or by attenuating the anti-apoptotic signaling of the phosphatidylinositol $3^{\prime}$-kinase (PI3K)-Akt (protein kinase B [PKB]) pathway elicited by insulin receptor activation $[46,48]$. Considering the strong correlation between insulin and left ventricular estimated mass found in this study, probably this pathway was activated in the animals. Clinical studies involving diabetes type 2, congestive heart failure, and obesity had correlated echocardiographic findings with insulin and lipid profile [49-52]. However, our model of diet-induced obesity showed an obesity-associated cardiomiopathy and brings new insights related to this condition and metabolic changes sought to elucidate whether this condition is correlated with metabolic changes.

There are recommendations to maintenance of target values of LDL cholesterol in order to protect against LV remodeling [53]. High-density lipoprotein (HDL) is one of the major lipoproteins in the blood. Studies have demonstrated that plasma HDL levels are inversely correlated with the incidence of coronary heart disease [54]. Post-infarct ejection fraction is lower in patients with low HDL cholesterol levels [55-57]. In addition, HDL cholesterol anti-inflammatory properties have been extensively discussed [58]. In vitro and in vivo studies suggest that the expression of Apo A1, the primary protein component of HDL cholesterol, is related with lower expressions of cell adhesion molecules ICAM-1 and VCAM-1 $[59,60]$ and lower expression of NF-kB and TNF- $\alpha$. Inflammatory cell infiltration and heart tissue inflammation have been implicated on pathophysiology of DCVs [61]. Although HDL cholesterol anti-inflammatory properties on cardiac remain under discussion [62], this is a possible mechanistic pathway for the explanation of the relationship between higher HDL cholesterol levels and an efficient systolic function.

\section{Conclusions}

In summary, this paper brings important findings, in a Wistar rats experimental model, following the consumption of a western diet that promoted cardiac remodeling. The diet employed in the current study was able to induce cardiac disorders related to metabolic parameters. However, more studies to investigate the causal mechanisms are necessary, which will allow the development of a new therapy target for clinical practice.

Author Contributions: A.J.T.F., F.V.F., J.L.G. and F.M. conducted the experiment; A.J.T.F., F.V.F., I.O.M., S.G.Z.B., K.A.H.K., C.R.C., F.M., C.C.V.d.A.S. and A.L.A.F. analyzed the data; and A.J.T.F., F.V.F., I.O.M., F.M and A.L.A.F. wrote the paper.

Funding: This work was funded by Conselho Nacional de Desenvolvimento Científico e Tecnólogico CNPq (424209/2016-0) and Fundação de Amparo à Pesquisa do Estado de São Paulo FAPESP 2018/22852-2 and Universidade Estadual Paulista "Julio de Mesquita Filho".

Conflicts of Interest: The authors declare no conflict of interest. 


\section{References}

1. Xia, J.; Zhang, Y.; Xin, L.; Kong, S.; Chen, Y.; Yang, S.; Li, K. Global transcriptomic profiling of cardiac hypertrophy and fatty heart induced by long-term high-energy diet in bama miniature pigs. PLoS ONE 2015, 10, e0132420. [CrossRef] [PubMed]

2. Sonestedt, E.; Hellstrand, S.; Drake, I.; Schulz, C.A.; Ericson, U.; Hlebowicz, J.; Persson, M.M.; Gullberg, B.; Hedblad, B.; Engström, G.; et al. Diet quality and change in blood lipids during 16 years of follow-up and their interaction with genetic risk for dyslipidemia. Nutrients 2016, 8, 274. [CrossRef] [PubMed]

3. Varlamov, O. Western-style diet, sex steroids and metabolism. Biochim. Biophys. Acta Mol. Basis Dis. 2017, 1863, 1147-1155. [CrossRef] [PubMed]

4. Magliano, D.J.; Shaw, J.E.; Zimmet, P.Z. How to best define the metabolic syndrome. Ann. Med. 2006, 38, 34-41. [CrossRef] [PubMed]

5. Flamment, M.; Arvier, M.; Gallois, Y.; Simard, G.; Malthièry, Y.; Ritz, P.; Ducluzeau, P.H. Fatty liver and insulin resistance in obese Zucker rats: No role for mitochondrial dysfunction. Biochimie 2008, 90, 1407-1413. [CrossRef] [PubMed]

6. Liu, R.H.; Mizuta, M.; Kurose, T.; Matsukura, S. Early events involved in the development of insulin resistance in Zucker fatty rat. Int. J. Obes. Relat. Metab. Disord. 2002, 26, 318-326. [CrossRef] [PubMed]

7. Bitar, M.S.; Al-Saleh, E.; Al-Mulla, F. Oxidative stress-Mediated alterations in glucose dynamics in a genetic animal model of type II diabetes. Life Sci. 2005, 77, 2552-2573. [CrossRef] [PubMed]

8. Cacanyiova, S.; Kristek, F. Adaptive vasoactive response to modulatory effects of endothelin-1 in spontaneously hypertensive rats. Pharmacol. Rep. 2008, 60, 941-949. [PubMed]

9. Marsh, S.A.; Dell'italia, L.J.; Chatham, J.C. Interaction of diet and diabetes on cardiovascular function in rats. Am. J. Physiol. Heart Circ. Physiol. 2008, 296, 282-292. [CrossRef] [PubMed]

10. Chen, D.; Wang, M.-W. Development and application of rodent models for type 2 diabetes. Diabetes Obes. Metab. 2005, 7, 307-317. [CrossRef] [PubMed]

11. Doggrell, S.A.; Brown, L. Rat models of hypertension, cardic hypertrophy and failure. Cardiovasc. Res. 1998, 39, 89-105. [CrossRef]

12. Carroll, J.F.; Zenebe, W.J.; Strange, T.B. Cardiovascular Function in a Rat Model of Diet-Induced Obesity. Hypertension 2006, 48, 65-72. [CrossRef] [PubMed]

13. Okere, I.C.; Chandler, M.P.; Mcelfresh, T.A.; Rennison, J.H.; Sharov, V.; Sabbah, H.N.; Tserng, K.Y.; Hoit, B.D.; Ernsberger, P.; Young, M.E.; et al. Differential effects of saturated and unsaturated fatty acid diets on cardiomyocyte apoptosis, adipose distribution, and serum leptin. Am. J. Physiol. Heart Circ. Physiol. 2006, 291, H38-H44. [CrossRef] [PubMed]

14. Ricci, E.; Chouabe, C.; Mertani, H.C.; Raccurt, M.; Smallwood, B.; Chouabe, C.; Bonvallet, R. Electrophysiological Characterization of Left Ventricular Myocytes from Obese Sprague-Dawley Rat. Obesity 2006, 14, 778-786. [CrossRef] [PubMed]

15. Panchal, S.K.; Poudyal, H.; Iyer, A.; Nazer, R.; Alam, A.; Diwan, V.; Kauter, K.; Sernia, C.; Campbell, F.; Ward, L.; et al. High-carbohydrate, High-fat Diet-Induced Metabolic Syndrome and Cardiovascular Remodeling in Rats. J. Cardiovasc. Pharmacol. 2011, 57, 611-624. [CrossRef] [PubMed]

16. Ferron, A.; Jacobsen, B.B.; Sant'Ana, P.; Campos, D.; Tomasi, L.; Luzivotto, R.; Cicogna, A.C.; Leopoldo, A.S.; Lima-Leopoldo, A.P. Cardiac Dysfunction Induced by Obesity Is Not Related to $\beta$-Adrenergic System Impairment at the Receptor-Signalling Pathway. PLoS ONE 2015, 10, e0138605. [CrossRef] [PubMed]

17. Carroll, J.F.; Jones, A.E.; Hester, R.L.; Reinhart, G.A.; Cockrell, K.; Mizelle, H.L. Reduced cardiac contractile responsiveness to isoproterenol in obese rabbits. Hypertension 1997, 30, 1376-1381. [CrossRef] [PubMed]

18. Relling, D.P.; Esberg, L.B.; Fang, C.X.; Johnson, W.T.; Murphy, E.J.; Carlson, E.C.; Saari, J.T.; Ren, J. High-fat diet-induced juvenile obesity leads to cardiomyocyte dysfunction and upregulation of Foxo3a transcription factor independent of lipotoxicity and apoptosis. J. Hypertens. 2006, 24, 549-561. [CrossRef] [PubMed]

19. Carroll, J.F.; Kyser, C.K.; Martin, M.M. beta-Adrenoceptor density and adenylyl cyclase activity in obese rabbit hearts. Int. J. Obes. Relat. Metab. Disord. 2002, 26, 627-632. [CrossRef] [PubMed]

20. Francisqueti, V.F.; Minatel, I.O.; Ferron, A.J.T.; Bazan, Z.; Silva, S.; de Campos, D.H.S.; Ferreira, A.L.; Moreto, F.; Cicogna, A.C.; et al. Effect of Gamma-Oryzanol as Therapeutic Agent to Prevent Cardiorenal Metabolic Syndrome in Animals Submitted to High Sugar-Fat Diet. Nutrients 2017, 9, 1299. [CrossRef] [PubMed] 
21. Xavier, H.T.; Izar, M.C.; Faria Neto, J.R.; Assad, M.H.; Rocha, V.Z.; Sposito, A.C.; Fonseca, F.A.; dos Santos, J.E.; Santos, R.D.; Bertolami, M.C.; et al. V Diretriz Brasileria de dislipidemia e prevenção da aterosclerose. Arq. Bras. Cardiol. 2013, 101, 1-20. [CrossRef] [PubMed]

22. Dahiya, R.; Shultz, S.P.; Dahiya, A.; Fu, J.; Flatley, C.; Duncan, D.; Cardinal, J.; Kostner, K.M.; Byrne, N.M.; Hills, A.P.; et al. Relation of reduced preclinical left ventricular diastolic function and cardiac remodeling in overweight youth to insulin resistance and inflammation. Am. J. Cardiol. 2015, 115, 1222-1228. [CrossRef] [PubMed]

23. Nagueh, S.F.; Smiseth, O.A.; Appleton, C.P.; Byrd, B.F.; Dokainish, H.; Edvardsen, T.; Flachskampf, F.A.; Gillebert, T.C.; Klein, A.L.; Lancellotti, P.; et al. Recommendations for the Evaluation of Left Ventricular Diastolic Function by Echocardiography: An Update from the American Society of Echocardiography and the European Association of Cardiovascular Imaging. J. Am. Soc. Echocardiogr. 2016, 29, 277-314. [CrossRef] [PubMed]

24. Sahn, D.J.; Demaria, A.; Kisslo, J. Recommendations Regarding Quantitation in M-Mode Echocardiography: Results of a Survey of Echocardiographic Measurements. Circulation 1978, 58, 1072-1083. [CrossRef] [PubMed]

25. Gomez-Smith, M.; Karthikeyan, S.; Jeffers, M.S.; Janik, R.; Thomason, L.A.; Stefanovic, B.; Corbett, D. A physiological characterization of the Cafeteria diet model of metabolic syndrome in the rat. Physiol. Behav. 2016, 16, 30260-30268. [CrossRef] [PubMed]

26. Buettner, R.; Parhofer, K.G.; Woenckhaus, M.; Wrede, C.E.; Kunz-Schughart, L.A.; Schölmerich, J.; Bollheimer, L.C. Defining high-fat-diet rat models: Metabolic and molecular effects of different fat types. J. Mol. Endocrinol. 2006, 36, 485-501. [CrossRef] [PubMed]

27. Yamashita, M.; Kumazoe, M.; Nakamura, Y.; Won, Y.S.; Bae, J.; Yamashita, S.; Tachibana, H. The Combination of Green Tea Extract and Eriodictyol Inhibited High-Fat/High-Sucrose Diet-Induced Cholesterol Upregulation Is Accompanied by Suppression of Cholesterol Synthesis Enzymes Synthesis Enzymes. J. Nutr. Sci. Vitaminol. 2016, 62, 249-256. [CrossRef] [PubMed]

28. Pons, Z.; Guerrero, L.; Margalef, M.; Arola, L.; Arola-Arnal, A.; Muguerza, B. Effect of low molecular grape seed proanthocyanidins on blood pressure and lipid homeostasis in cafeteria diet-fed rats. J. Physiol. Biochem. 2005, 70, 629-637. [CrossRef] [PubMed]

29. Sclafani, A.; Berner, C.N. Influence of diet palatability on the meal taking behavior of hypothalamic hyperphagic and normal rats. Physiol. Behav. 1976, 16, 355-363. [CrossRef]

30. Sampey, B.P.; Vanhoose, A.M.; Winfield, H.M.; Freemerman, A.J.; Muehlbauer, M.J.; Fueger, P.T.; Newgard, C.B.; Makowski, L. Cafeteria diet is a robust model of human metabolic syndrome with liver and adipose inflammation: Comparison to high-fat diet. Obesity 2011, 19, 1109-1117. [CrossRef] [PubMed]

31. Quesada, H.; del Bas, J.M.; Pajuelo, D.; Díaz, S.; Fernandez-Larrea, J.; Pinent, M.; Arola, L.; Salvadó, M.J.; Bladé, C. Grape seed proanthocyanidins correct dyslipidemia associated with a high-fat diet in rats and repress genes controlling lipogenesis and VLDL assembling in liver. Int. J. Obes. 2009, 33, 1007-1012. [CrossRef] [PubMed]

32. du Toit, E.F.; Nabben, M.; Lochner, A. A potential role for angiotensin II in obesity induced cardiac hypertrophy and ischaemic/reperfusion injury. Basic Res. Cardiol. 2005, 100, 346-354. [CrossRef] [PubMed]

33. Coatmellec-Taglioni, G. Sexual Dimorphism in Cafeteria Diet-Induced Hypertension Is Associated with Gender-Related Difference in Renal Leptin Receptor Down-Regulation. J. Pharmacol. Exp. Ther. 2003, 305, 362-367. [CrossRef] [PubMed]

34. Coatmellec-Taglioni, G.; Dausse, J.P.; Ribière, C.; Giudicelli, Y. Hypertension in cafeteria-fed rats: Alterations in renal $\alpha 2$-adrenoceptor subtypes. Am. J. Hypertens. 2000, 13, 529-534. [CrossRef]

35. Howitt, L.; Sandow, S.L.; Grayson, T.H.; Ellis, Z.E.; Morris, M.J.; Murphy, T.V. Differential effects of diet-induced obesity on BKCa $\beta 1$-subunit expression and function in rat skeletal muscle arterioles and small cerebral arteries. Am. J. Physiol. Heart Circ. Physiol. 2011, 301, H29-H40. [CrossRef] [PubMed]

36. Pasarín, M.; La Mura, V.; Gracia-Sancho, J.; García-Calderó, H.; Rodríguez-Vilarrupla, A.; García-Pagán, J.C.; Bosch, J.; Abraldes, J.G. Sinusoidal endothelial dysfunction precedes inflammation and fibrosis in a model of NAFLD. PLoS ONE 2012, 7, e32785. [CrossRef] [PubMed]

37. Leopoldo, A.S.; Sugizaki, M.M.; Lima-Leopoldo, A.P.; do Nascimento, A.F.; Luvizotto, R.D.A.M.; de Campos, D.H.S.; Okoshi, K.; Dal Pai-Silva, M.; Padovani, C.R.; Cicogna, A.C. Cardiac remodeling in a rat model of diet-induced obesity. Can. J. Cardiol. 2010, 26, 423-429. [CrossRef] 
38. Vileigas, D.F.; de Deus, A.F.; da Silva, D.C.; de Tomasi, L.C.; de Campos, D.H.; Adorni, C.S.; de Oliveira, S.M.; Sant'Ana, P.G.; Okoshi, K.; Padovani, C.R.; et al. Saturated high-fat diet-induced obesity increases adenylate cyclase of myocardial $\beta$-adrenergic system and does not compromise cardiac function. Physiol. Rep. 2016, 4. [CrossRef] [PubMed]

39. Goncalves, N.; Silva a, F.; Rodrigues, P.G.; Correia, E.; Moura, C.; Eloy, C.; Roncon-Albuquerque, R., Jr.; Falcão-Pires, I.; Leite-Moreira, A.F. Early cardiac changes induced by a hypercaloric diet in "subclinical" obesity. Am. J. Physiol. Heart Circ. Physiol. 2016, 310, H655-H666. [CrossRef] [PubMed]

40. Chahal, H.; McClelland, R.L.; Tandri, H.; Jain, A.; Turkbey, E.B.; Hundley, W.G.; Barr, R.G.; Kizer, J.; Lima, J.A.; Bluemke, D.A.; et al. Obesity and right ventricular structure and function: The MESA-right ventricle study. Chest 2012, 141, 388-395. [CrossRef] [PubMed]

41. Eschalier, R.; Rossignol, P.; Kearney-Schwartz, A.; Adamopoulos, C.; Karatzidou, K.; Fay, R.; Mandry, D.; Marie, P.Y.; Zannad, F. Features of cardiac remodeling, associated with blood pressure and fibrosis biomarkers, are frequent in subjects with abdominal obesity. Hypertension 2014, 63, 740-746. [CrossRef] [PubMed]

42. Rider, O.J.; Lewis, A.J.M.; Lewandowski, A.J.; Ntusi, N.; Nethononda, R.; Petersen, S.E.; Francis, J.M.; Pitcher, A.; Banerjee, R.; Leeson, P.; et al. Obese subjects show sex-specific differences in right ventricular hypertrophy. Circ. Cardiovasc. Imaging 2014, 8, e002454. [CrossRef] [PubMed]

43. Skurk, T.; Alberti-huber, C.; Herder, C.; Hauner, H. Relationship between Adipocyte Size and Adipokine Expression and Secretion. J. Clin. Endocrinol. Metab. 2016, 92, 1023-1033. [CrossRef] [PubMed]

44. Abel, E.D.; Litwin, S.E.; Sweeney, G. Cardiac Remodeling in Obesity. Physiol. Rev. 2008, 88, $389-419$. [CrossRef] [PubMed]

45. Frey, N.; Katus, H.A.; Olson, E.N.; Hill, J.A. Hypertrophy of the Heart: A New Therapeutic Target? Circulation 2004, 109, 1580-1589. [CrossRef] [PubMed]

46. Rider, O.J.; Francis, J.M.; Ali, M.K.; Byrne, J.; Clarke, K.; Neubauer, S.; Petersen, S.E. Determinants of left ventricular mass in obesity; a cardiovascular magnetic resonance study. J. Cardiovasc. Magn. Reson. 2009, 11, 9. [CrossRef] [PubMed]

47. Wensley, I.; Salaveria, K.; Bulmer, A.C.; Donner, D.G.; du Toit, E.F. Myocardial structure, function and ischaemic tolerance in a rodent model of obesity with insulin resistance. Exp. Physiol. 2013, 98, 1552-1564. [CrossRef] [PubMed]

48. Dhanasekaran, A.; Gruenloh, S.K.; Buonaccorsi, J.N.; Zhang, R.; Gross, G.J.; Falck, J.R.; Patel, P.K.; Jacobs, E.R.; Medhora, M. Multiple antiapoptotic targets of the PI3K/Akt survival pathway are activated by epoxyeicosatrienoic acids to protect cardiomyocytes from hypoxia/anoxia. Am. J. Physiol. Heart Circ. Physiol. 2008, 294, H724-H735. [CrossRef] [PubMed]

49. Orhan, A.L.; Uslu, N.; Dayi, S.U.; Nurkalem, Z. Effects of Isolated Obesity on Left and Right Ventricular Function: A Tissue Doppler and Strain Rate Imaging Study. Echocardiography 2010, 27, 236-243. [CrossRef] [PubMed]

50. de Courten, B.; Kurdiova, T.; de Courten, M.P.; Belan, V.; Everaert, I.; Vician, M.; Teede, H.; Gasperikova, D.; Aldini, G.; Derave, W.; et al. Muscle Carnosine Is Associated with Cardiometabolic Risk Factors in Humans. PLoS ONE 2015, 10, e0138707. [CrossRef] [PubMed]

51. Barbosa, M.M.; Beleigoli, A.M.; De Fatima Diniz, M.; Freire, C.V.; Ribeiro, A.L.; Nunes, M.C.P. Strain imaging in morbid obesity: Insights into subclinical ventricular dysfunction. Clin. Cardiol. 2011, 34, $288-293$. [CrossRef] [PubMed]

52. Fidan-Yaylali, G.; Yaylali, Y.T.; Erdogan, Ç.; Can, B.; Senol, H.; Gedik-Topçu, B.; Topsakal, S. The Association between Central Adiposity and Autonomic Dysfunction in Obesity. Med. Princ. Prat. 2016, 25, 442-448. [CrossRef] [PubMed]

53. Buono, F.; Spinelli, L.; Giallauria, F.; Assante Di Panzillo, E.; Di Marino, S.; Ferrara, F.; Vigorito, C.; Trimarco, B.; Morisco, C. Usefulness of satisfactory control of low-density lipoprotein cholesterol to predict left ventricular remodeling after a first ST-elevation myocardial infarction successfully reperfused. Am. J. Cardiol. 2011, 107, 1772-1778. [CrossRef] [PubMed]

54. Yin, K.; Agrawal, D.K. High-Density Lipoprotein: A Novel Target for Antirestenosis Therapy. Clin. Transl. Sci. 2014, 7, 500-511. [CrossRef] [PubMed]

55. Gordts, S.C.; Muthuramu, I.; Nefyodova, E.; Jacobs, F.; Van Craeyveld, E.; De Geest, B. Beneficial effects of selective HDL-raising gene transfer on survival, cardiac remodelling and cardiac function after myocardial infarction in mice. Gene Ther. 2013, 20, 1053-1061. [CrossRef] [PubMed] 
56. Wang, T.D.; Wu, C.C.; Chen, W.J.; Lee, C.M.; Chen, M.F.; Liau, C.S.; Lee, Y.T. Dyslipidemias have a detrimental effect on left ventricular systolic function in patients with a first acute myocardial infarction. Am. J. Cardiol. 1998, 81, 531-537. [CrossRef]

57. Kempen, H.J.; van Gent, C.M.; Buytenhek, R.; Buis, B. Association of cholesterol concentrations in low-density lipoprotein, high-density lipoprotein, and high-density lipoprotein subfractions, and of apolipoproteins AI and AII with coronary stenosis and left ventricular function. J. Lab. Clin. Med. 1987, 109, 19-26. [PubMed]

58. Barter, P.J.; Puranik, R.; Rye, K.A. New insights into the role of HDL as an anti-inflammatory agent in the prevention of cardiovascular disease. Curr. Cardiol. Rep. 2007, 9, 493-498. [CrossRef] [PubMed]

59. Cockerill, G.W.; Rye, K.-A.; Gamble, J.R.; Vadas, M.A.; Barter, P.J. High-Density Lipoproteins Inhibit Cytokine-Induced Expression of Endothelial Cell Adhesion Molecules. Arterioscler. Thromb. Vasc. Biol. 1995, 15, 1987-1994. [CrossRef] [PubMed]

60. Calabresi, L.; Franceschini, G.; Sirtori, C.R.; De Palma, A.; Saresella, M.; Ferrante, P.; Taramelli, D. Inhibition of VCAM-1 expression in endothelial cells by reconstituted high density lipoproteins. Biochem. Biophys. Res. Commun. 1997, 238, 61-65. [CrossRef] [PubMed]

61. Libby, P. Inflammation and cardiovascular disease mechanisms. Am. J. Clin. Nutr. 2006, 83, 456S-460S. [CrossRef] [PubMed]

62. Namiri-Kalantari, R.; Gao, F.; Chattopadhyay, A.; Wheeler, A.A.; Navab, K.D.; Farias-Eisner, R.; Reddy, S.T. The dual nature of HDL: Anti-Inflammatory and pro-Inflammatory. BioFactors 2015, 41, 153-159. [CrossRef] [PubMed]

(C) 2018 by the authors. Licensee MDPI, Basel, Switzerland. This article is an open access article distributed under the terms and conditions of the Creative Commons Attribution (CC BY) license (http:/ / creativecommons.org/licenses/by/4.0/). 